\title{
Connexin43 knockdown in bone marrow-derived dendritic cells by small interfering RNA leads to a diminished T-cell stimulation
}

\author{
FULING YU, HUI YAN, WENCHENG NIE and JIANHUA ZHU \\ Cardiovascular Department, The First Affiliated Hospital, College of Medicine, \\ Zhejiang University, Hangzhou, Zhejiang 310003, P.R. China
}

Received November 3, 2014; Accepted August 25, 2015

DOI: $10.3892 / \mathrm{mmr} .2015 .4593$

\begin{abstract}
Dendritic cells, the most powerful type of antigen-presenting cells, have the unique ability to induce primary immune responses. Connexin43 expression is upregulated to increase gap junctions when immune cells are exposed to inflammatory factors. The present study applied small-interfering RNA (siRNA) to decrease connexin43 expression. The results showed that silencing of connexin 43 using siRNA resulted in arrest of bone marrow-derived dendritic cell (BM-DC) maturation as evidenced by reduced expression of major histocompatibility complex II, CD40, CD80 and CD86. Functionally, connexin43-silenced BM-DC showed a markedly decreased capability to induce T-cell stimulation. In conclusion, the present study demonstrated that antigens present on BM-DCs can be suppressed by connexin43 knockdown in BM-DCs. The present study therefore presented an effective method to modulate the immunology of BM-DCs.
\end{abstract}

\section{Introduction}

As the most powerful antigen-presenting cell (APC), dendritic cells (DCs) have a critical role in the stimulation of immune tolerance. Upon capturing of antigens, DCs migrate to the lymph nodes and transfer antigenic epitopes to $\mathrm{T}$ cells, which leads to activation of T cells (1-3). The surface expression of major histocompatibility complex (MHC) and co-stimulatory molecules, including CD40, CD80 and CD86, are upregulated in DCs upon their functional transformation from 'tolerogenic' to 'immunogenic' DCs (4).

The gap junction is a specialized intercellular connection between a multitude of cell-types of higher organisms.

Correspondence to: Professor Jianhua Zhu, Cardiovascular Department, The First Affiliated Hospital, College of Medicine, Zhejiang University, 79 Qingchun Road, Hangzhou, Zhejiang 310003, P.R. China

E-mail: yufuling1583@126.com

Key words: dendritic cells, connexin43, small interfering RNA, silencing, bone marrow-derived dendritic cells
Connexins (Cx) are members of a diverse family of proteins that are differentially produced by a number of cell types $(5,6)$. Two connexin-based hemichannels are coupled to form a gap junction between two adjacent cells $(7,8)$. Gap junctions formed by $\mathrm{Cx}(\leq 1 \mathrm{kDa}$ in size) have an important role in transmitting signals between cells of the immune system (9-14). As one of the principal connexins in the immune system, the expression of connexin43 (Cx43) is upregulated in human monocytes and DCs at inflammatory sites to form gap junctions when immune cells are exposed to inflammatory factors (15). Neijssen et al (16) found that monocytes or DCs interacted with their environment to source metabolic or electronic information from the neighboring cells upon detecting inflammation. These results revealed a novel mechanism of cross-presentation through gap junctions. Therefore, suppression of Cx43 may be an important strategy for immune therapy.

RNA interference (RNAi), which sequence-specifically targets mRNAs with short double-stranded (ds)RNAs, has been successfully employed in various mammalian cell lines as well as in primary cells, including $\mathrm{T}$ lymphocytes and antigen-presenting cells. In previous studies, knockdown of various cytokines has successfully generated desired immune responses $(17,18)$. DNA vectors, adenoviruses as well as lentiviruses have been widely applied for small interfering (si) RNA delivery into a variety of cell systems $(19,20)$. Among the methods for the delivery of siRNA into DCs, chemical transfection (e.g. using lipid-based reagents) and viral vectors are routinely used $(21,22)$. However, chemical transfection reagents are prone to causing allergic reactions and the application of lentiviral vectors may result in unspecific immune responses (23). In order to circumvent these undesired effects, a transfection method exclusively relying on physical reactions is urgently required to downregulate specific protein expression. Jantsch et al (24) previously established an electroporation protocol to deliver siRNA molecules into bone marrow-derived dendritic cells (BM-DCs) without affecting the immunoresponse of DCs.

The present study reported on the application an efficient method of electroporation to knock down Cx43 expression in BM-DCs by using siRNA. Three prospective dsRNAs targeting Cx43 were applied and reverse-transcription quantitative polymerase chain reaction (RT-qPCR) was used to identify the dsRNA with the most potent Cx43 knockdown ability following transfection under electroporation conditions. After 
knockdown of $\mathrm{Cx} 43$ expression, the surface antigens of DCs were assessed by flourescence-assisted cell sorting (FACS) and their capacity to activate $\mathrm{T}$ cells was evaluated using a mixed lymphocyte reaction (MLR). The results of the present study provided evidence that $\mathrm{Cx} 43$ has an important role in the immunomodulation of DCs.

\section{Materials and methods}

Generation of BM-DCs. A total of 20 adult male C57BL/6 and BALB/c mice (2 months old; weight, $25 \mathrm{~g}$ ), obtained from the Animal Laboratory of Zhejiang University (Hangzhou, China) were raised under a 12 -h light/dark cycle at $22 \pm 1^{\circ} \mathrm{C}, 60 \pm 5 \%$ humidity, and access to food and water ad libitum. The present study was approved by the ethics committee of the College of Medicine, Zhejiang University (Hangzhou, China).

The animals were sacrificed by decapitation under anesthesia with $1 \%$ sodium pentobarbital (Merck, Darmstadt, Germany). BM-DCs were generated from bone marrow progenitor cells according to the protocol of a previous study (25). Briefly, bone marrow cells were flushed from the femurs and tibias of C57BL/6 mice, followed by washing and culture in six-well plates $\left(2 \times 10^{6}\right.$ cells $\left./ \mathrm{ml}\right)$ in $2 \mathrm{ml}$ RPMI 1640 medium containing $2 \mathrm{mM}$ L-glutamine and $10 \%$ fetal calf serum (FCS) (all from Gibco-BRL, Invitrogen Life Technologies, Inc., Carlsbad, CA, USA), supplemented with recombinant Granulocyte-macrophage colony-stimulating factor (GM-CSF; 20 ng/ml; PeproTech, Rocky Hill, NJ, USA) and recombinant mouse interleukin (IL)-4 (10 ng/ml; PeproTech). All cultures were incubated at $37^{\circ} \mathrm{C}$ in an incubator containing a humidified atmosphere with $5 \% \mathrm{CO}_{2}$. After $48 \mathrm{~h}$ of culture, non-adherent granulocytes were removed by washing and fresh medium was added. DCs were cultured for six days as immature DCs. Activation with lipopolysaccharide (LPS; 100 ng/ml; Sigma-Aldrich, St. Louis, MO, USA) was performed after eight days of culture, and following $48 \mathrm{~h}$, DCs differentiated into mature DCs (mDC).

siRNA synthesis. siRNA sequences were selected in accordance with a previously described method $(26,27)$. Three sequences specific for the $\mathrm{Cx} 43$ gene were selected: Cx43-targeting dsRNA 1 (5'-CCCACCTTTGTGTCTTCCATA-3'), 2 (5'-GCAGATTGAAATCAAGAAGTT-3') and 3 (5'-CCTGCTGAGAACCTACATCAT-3'). Non-silencing control siRNA (5'-TTCTCCGAACGTGTCACGT-3') is an irrelevant siRNA with random nucleotides. All siRNAs were synthesized and annealed by Shanghai GeneChem Limited Co. (Shanghai, China).

Electroporation of DCs. DCs were harvested and washed with RPMI 1640 and phosphate-buffered saline at room temperature. The cells were suspended in optimized minimum essential medium (Opti-MEM; Invitrogen Life Technologies, Inc.) at a concentration of $4 \times 10^{7}$ cells $/ \mathrm{ml}$. $7.5 \mu \mathrm{g}$ siRNA duplexes were transferred to a 4-mm cuvette (Tiancheng Company, Hangzhou, China) and filled up to a final volume of $100 \mu 1$ with Opti-MEM. $100 \mu$ l cell suspension (containing $4 \times 10^{6}$ cells) was added and immediately pulsed using a Gene Pulser II apparatus (Bio-Rad Laboratories, Inc., Hercules, CA, US). Pulse conditions were $300 \mathrm{~V}, 150 \mu \mathrm{F}$ and
$100 \Omega$. Immediately after $\sim 2$ sec electroporation, the cells were transferred into medium supplemented with GM-CSF and IL-4.

$R T$ - $q P C R$. After gene silencing, mRNA was extracted from DCs using TRIzol (Invitrogen Life Technologies, Inc.) according to the manufacturer's instructions. The SuperScript Pre-amplification system kit (Invitrogen Life Technologies, Inc.) was used for the generation of the first-strand cDNA. In brief, $0.5 \mu \mathrm{g}$ oligo (dT) (12-18 bp) and $200 \mathrm{U}$ SuperScript-2 reverse transcriptase were incubated with $2 \mu \mathrm{g}$ DNA-free total RNA for $50 \mathrm{~min}$ at $42^{\circ} \mathrm{C}$ in the presence of $0.5 \mathrm{mM}$ desoxynucleotide triphosphate, $10 \mathrm{mM}$ dithiothreitol and $1 \mathrm{X}$ first-strand buffer. The following primers (Sangon Biotech Co., Ltd., Shanghai, China) were used: Cx43 (519 bp) sense, 5'-CCCCACTCTCACCTATGTCTCC-3' and anti-sense, 5'-ACTTTTGCCGCCTAGCTATCCC-3'; and GAPDH (172 bp) sense, 5'-ATTCAACGGCACAGTCAAGG-3' and anti-sense, 5'-GCAGAAGGGGCCGGAGATGA-3'. qPCR was performed on an ABI 7900 PCR Instrument (PerkinElmer, Inc., Waltham, MA, USA) in a $20 \mu 1$ volume, using 5x Universal SYBR Green PCR Master Mix (Takara Bio Inc., Otsu, Japan). GAPDH was used as an internal control. PCR was performed based on following protocol: Initial denaturation at $95^{\circ} \mathrm{C}$ for 5 min, followed by 30 cycles of denaturation at $95^{\circ} \mathrm{C}$ for $0.5 \mathrm{~min}$, re-naturation at $60^{\circ} \mathrm{C}$ for $0.5 \mathrm{~min}$ and extension at $72^{\circ} \mathrm{C}$ for $0.5 \mathrm{~min}$, followed by a final extension at $72^{\circ} \mathrm{C}$ for $10 \mathrm{~min}$. Results were obtained from at least three independent experiments performed in triplicate. The expression levels were quantified using the $\Delta \Delta \mathrm{CT}$ method.

Cell viability assay. The cell viability after electroporation was determined using Trypan blue staining. Dendritic cells were collected $48 \mathrm{~h}$ after electroporation, stained with Trypan blue (Beyotime Institute of Biotechnology, Inc., Haimen, China) and counted using a hematocytometer (Hangzhou Kanna Tech Co. Ltd, Hangzhou, China). Four different populations of electroporated cells were generated: i) DC; ii) DC electroporated without siRNA; iii) DC electroporated with non-silencing control siRNA; iv) DC electroporated with Cx43-targeting SiRNA 2.

Western blot analysis. DCs $\left(4 \times 10^{6}\right)$ were lysed in $150 \mu 1$ lysis buffer containing $10 \%$ glycerol, 2 mM EDTA (pH 8.0), $0.5 \%$ Nonidet P-40, $137 \mathrm{mM} \mathrm{NaCl}$ and $50 \mathrm{mM}$ Tris- $\mathrm{HCl}(\mathrm{pH} 8.0)$ (Beyotime Institute of Biotechnology, Inc.). Protein concentration was determined using a bicinchoninic acid assay (Beyotime Institute of Biotechnology, Inc.) and $20 \mu \mathrm{g}$ protein was separated using $12 \%$ SDS-PAGE following transfer onto a nitrocellulose membrane. The following primary antibodies were used for western blot analysis, and incubated at $4{ }^{\circ} \mathrm{C}$ overnight: Mouse anti-Cx43 monoclonal antibody (mAb; Sigma-Aldrich; 1:8,000) and mouse anti-GAPDH mAb (clone 6c5, Kang Chen, China; 1:1,000). After incubation with goat anti-mouse horseradish peroxidase-labeled immunoglobulin $\mathrm{G}$ secondary antibodies (1:10,000, $2 \mathrm{~h}$ at room temperature), the blots were washed three times with phosphate-buffered saline for $10 \mathrm{~min}$, signal detection was performed using an enhanced chemiluminescence western blotting substrate (Pierce Biotechnology, Inc., Rockford, IL, USA), and the 


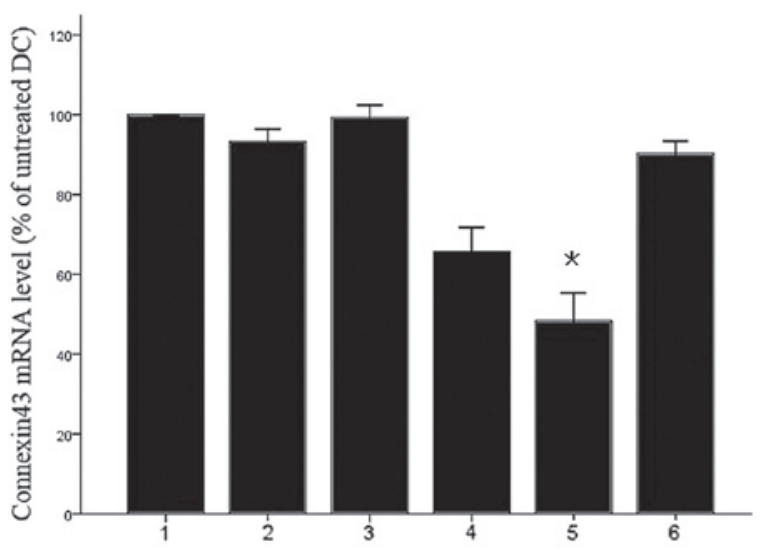

Figure 1. Identification of an efficient and specific siRNA duplex for connexin43 knockdown. DCs were electroporated with $7.5 \mu \mathrm{g}$ of various connexin43-siRNA duplexes and maturation was induced $4 \mathrm{~h}$ after electroporation. After $24 \mathrm{~h}$ of maturation, connexin 43 mRNA was quantified by reverse-transcription quantitative polymerase chain reaction with GAPDH as an internal control. The normalized ratio of connexin43 to GAPDH in untreated cells was set as $100 \%$. DCs electroporated without any siRNA demonstrated no significant downregulation of connexin 43 mRNA. A significant knockdown of connexin 43 mRNA by up to $45 \%$ was detected for DC plus connexin 43 target 2 dsRNA. Values are expressed as the mean \pm standard deviation of three independent experiments. ${ }^{*} \mathrm{P}<0.05$ vs. untreated cells. Lanes $1, \mathrm{DC} ; 2$, DC electroporated without siRNA; 3, DC plus non-silencing control siRNA; 4, DC connexin43-targeting dsRNA 1; 5, DC plus connexin43-targeting dsRNA 2; 6 , DC plus connexin43-targeting dsRNA 3. siRNA, small interfering RNA; DC, dendritic cells; dsRNA, double-stranded RNA.

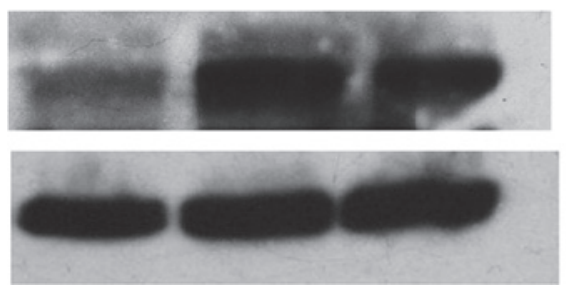

CX43

GAPDH
Figure 2. Western blot analysis of Cx43. Effects of siRNA on Cx43 levels in DC. Lanes: 1, DC plus Cx43-targeting dsRNA 2; 2, DC; 3, DC electroporated without siRNA. DCs electroporated with Cx43-targeting dsRNA 2 showed markedly reduced $\mathrm{Cx} 43$ levels when compared with those of untreated and electroporated cells. After $48 \mathrm{~h}$, the total cellular protein extract of electroporated DCs was separated by $12 \%$ SDS-PAGE and Cx43 was detected using an anti- $\mathrm{Cx} 43 \mathrm{Ab}$. Subsequently, the membranes were stripped and re-probed with an anti-GAPDH Ab. While untreated DCs and electroporated DCs showed almost equal expression levels of Cx43, DCs electroporated with Cx43-targeting 2 dsRNA showed markedly reduced levels of Cx43. The blots are representative of two independent experiments with cells from different mice. DC, dendritic cells; dsRNA, double-stranded RNA; Cx, connexin; Ab, antibody.

blots were scanned using Bio-Rad ChemiDoc XRS (Bio-Rad Laboratories, Inc.).

Flow cytometric analysis. Phenotypic analysis of isolated or cultured DCs was performed on a FACScan flow cytometer (BD Biosciences, Franklin Lakes, NJ, USA). All antibodies (fluorescein isothiocyanate-conjugated anti-mouse CD40 and CD80 antibodies, and PE-conjugated anti-mouse MHC-II and CD86 antibodies) were purchased from eBioscience, Inc. (San Diego, CA, USA). DC sub-sets were analyzed by means of two- or three-color staining with various combinations of

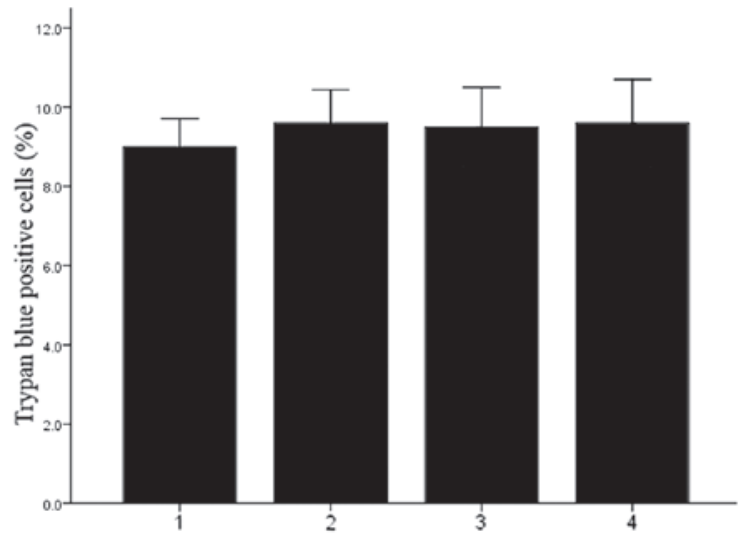

Figure 3. Electroporation of DC with connexin43-targeting dsRNA 2 and without siRNA did not significantly increase the number of dead cells after $48 \mathrm{~h}$, as indicated by Typan blue staining. Values are presented as the mean \pm standard deviation of three independent experiments performed on cells from different mice. Lanes: 1, DC; 2, DC electroporated without siRNA; 3, DC plus non-silencing control siRNA; 4, DC connexin43-targeting dsRNA 2. siRNA, small interfering RNA; DC, dendritic cells; dsRNA, double-stranded RNA.

mouse antibodies. All FACS analyses were performed using appropriate isotype controls (eBioscience, Inc).

MLR analysis. DCs from the different experimental groups were treated with $30 \mu \mathrm{g} / \mathrm{ml}$ mitomycin C (Sigma-Aldrich) at $37^{\circ} \mathrm{C}$ for $1 \mathrm{~h}$, washed twice with RPMI 1640 and seeded into flat-bottom 96 -well culture plates $\left(10^{4} /\right.$ well) for use as stimulator cells. Recipient T cells $\left(0.2-1 \times 10^{6} /\right.$ well) from BALB/c mice were added to the DCs in a total volume of $200 \mu \mathrm{l}$ RPMI 1640 containing 10\% FCS, followed by co-culture in a humidified atmosphere with $5 \% \mathrm{CO}_{2}$ at $37^{\circ} \mathrm{C}$ for $72 \mathrm{~h} .3 \mathrm{~h}$ prior to the end of the culture, Cell Counting kit- 8 solution (Beyotime Institute of Biotechnology, Inc.) was added to each well of the plate $(10 \mu \mathrm{l} /$ well). At the end of the culture, the absorbance at $450 \mathrm{~nm}$ was measured using a microplate reader 3550 (Bio-Rad Laboratories, Inc.).

Statistical analysis. Values are expressed as the mean \pm standard deviation. Statistical analysis was performed using SPSS 17.0 software (SPSS, Inc., Chicago, IL, USA). MLR and RT-qPCR data were analyzed using one-way analysis of variance followed by the Newman-Keuls test. $\mathrm{P}<0.05$ was considered to indicate a statistically significant difference between values.

\section{Results}

Silencing of Cx43 in DCs. In order to identify an siRNA duplex that is able to reduce the expression of $\mathrm{Cx} 43$, three candidate dsRNAs were synthesized. Following dsRNA-mediated knockdown with electroporation, transcripts of $\mathrm{Cx} 43$ were detected by RT-qPCR. After transfection for $24 \mathrm{~h}$, a marked downregulation of Cx43 mRNA levels in Cx43 dsRNA-transfected cells, but not in scrambled siRNA-transfected cells, was observed compared to that in the untreated DCs (Fig. 1). Cx43-targeting dsRNA 2 was the most effective siRNA to block $\mathrm{Cx} 43$ expression at the mRNA level. The protein levels of $\mathrm{Cx} 43$ were also detected in the transfection groups. 


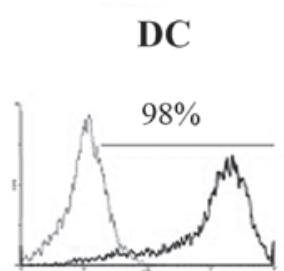

CD40-FITC

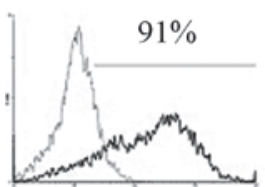

CD80-FITC

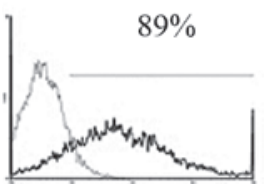

MHC-II-PE

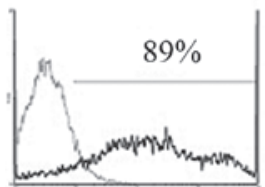

CD86-PE
DC-electroporated without siRNA

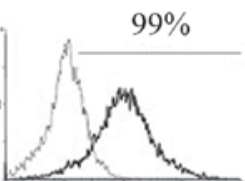

CD40-FITC

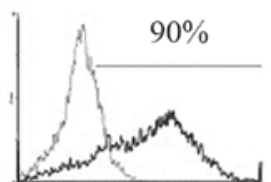

CD40-FITC

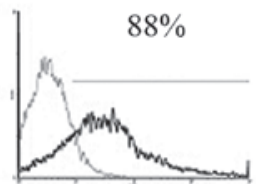

MHC-II-PE

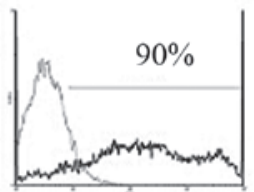

CD86-PE
DC plus cx43 siRNA

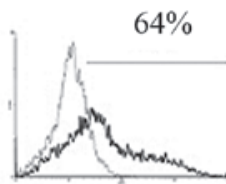

CD40-FITC

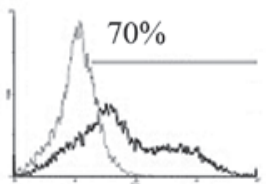

CD40-FITC

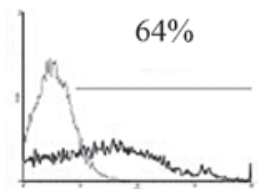

MHC-II-PE

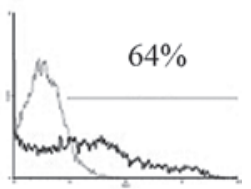

CD86-PE
Figure 4. Fluorescence-assisted cell sorting analyses of the surface expression of co-stimulatory markers CD40, CD80, CD86 and MHC-II. Immature DCs were either left untreated, electroporated without siRNA or electroporated with $7.5 \mu \mathrm{g} \mathrm{Cx} 43$-targeting dsRNA 2. The expression of co-stimulatory markers CD40, CD80, CD86 and MHC-II in DC were decreased in the Cx43 siRNA target 2 group. Grey histogram graphs indicate fluorescence in the absence of specific antibody. Histograms are representative of three independent experiments performed on cells from different mice. siRNA, small interfering RNA; DC, dendritic cells; dsRNA, double-stranded RNA; MHC, major histocompatibility complex; PE, phycoerythrin; FITC, fluorescein isothiocyanate; $\mathrm{Cx}$, connexin.

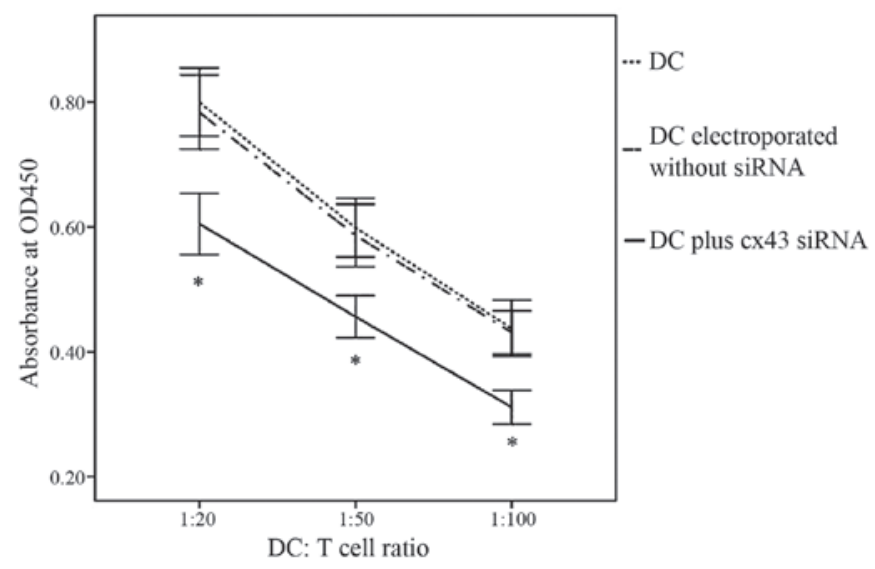

Figure 5. Mature DCs Cx43 electroporated with siRNA showed a reduced capacity to stimulate allogenic T cells. Immature DCs were electroporated with 7.5 $\mu \mathrm{g}$ Cx43-targeting siRNA 2, matured for $48 \mathrm{~h}$ and co-incubated with allogeneic T cells for $72 \mathrm{~h}$. A Cell Counting Kit- 8 assay was employed to assess cell viability, which was relative to the absorbance at $450 \mathrm{~nm}$. DCs that were electroporated with $\mathrm{Cx} 43$-targeting siRNA 2 showed a markedly reduced capacity to induce T-cell proliferation when compared with that of DCs that were electroporated without siRNA or untreated. Values are presented as the mean \pm standard deviation of three independent experiments performed on cells from different mice. "P<0.05, vs. DCs without siRNA. OD, optical density; siRNA, small interfering RNA; DC, dendritic cells; dsRNA, double-stranded RNA.
Consistent with the effects on Cx43 mRNA expression, $\mathrm{Cx} 43$ protein was also significantly reduced after transfection with Cx43-targeting dsRNA 2 (Fig. 2).

Transfection of DCs with Cx43-targeting dsRNA under electroporation does not affect cell viability. The viability of DCs was determined by Trypan blue staining. As shown in Fig. 3, the viability was similar among all experimental groups, indicating that electroporation-mediated $\mathrm{Cx} 43$ knockdown did not affect the viability of DCs $(\mathrm{P}>0.05)$.

Transfection of DCs with Cx43-targeting dsRNA under electroporation decrease the expression of surface antigens. After six days of culture, transfected DCs were stimulated with LPS for $48 \mathrm{~h}$ and subsequently collected. The expression of surface co-stimulatory molecules was assessed by FACS analysis. The surface expression of CD40, CD80, MHC-II and CD86 on untreated DCs, DCs that were electroporated without siRNA and DCs that were electroporated in the presence of Cx43-targeting dsRNA was assessed following $48 \mathrm{~h}$. As shown in Fig. 3, the fraction of cells expressing CD40, MHC-II, CD80 and CD86 was decreased in DCs with Cx43 knockdown compared with that in the other groups.

Cx43-knockdown DCs show a reduced capacity to stimulate $T$ cells. In order to assess whether $\mathrm{Cx} 43$ knockdown affected the stimulatory effects of DCs on T-cell proliferation, an allogeneic MLR was performed. DCs that were electroporated in the presence of Cx43-targeting dsRNA 2 exhibited a markedly reduced capacity to stimulate T-cell proliferation compared with that of untreated DCs or those subjected to electroporation only (Fig. 5). These results demonstrated that $\mathrm{Cx} 43 \mathrm{had}$ a specific role in DC-mediated T-cell stimulation.

\section{Discussion}

In response to inflammatory reactions, DCs or monocytes/macrophages upregulate $\mathrm{Cx} 43$ expression and form gap junctions at the inflammation site in order to link and therefore aggregate cells of identical as well as of different types $(15,16)$. A recent study by our group further supported that $\mathrm{Cx} 43$ has critical roles in mediating the maturation of DCs as well as T-cell stimulation.

Mendoza-Naranjo et al (28) reported that gap junction formation was inhibited by a specific $\mathrm{Cx}$-mimetic peptide, which binds to $\mathrm{Cx} 43$ extracellular loop 1 at the plasma membrane surface, which hampered human DCs from acquiring melanoma antigens from adjacent cells and inhibited melanoma-specific T-cell activation. Consistently with these results, gap junction inhibitors also affected the antigen transfer between human DCs $(29,30)$. These findings suggested that membrane expression of $\mathrm{Cx} 43$ in DCs is closely associated with antigen transfer. A further study revealed that $\mathrm{Cx} 43$ is required for correcting T-cell maturation as demonstrated in Cx43-deficient mice (31).

For treatment regimens of various conditions, including autoimmune diseases, organ transplantation and cancer, immunomodulation is critical. Since the immunogenic potential of DCs is among the most important factors in generating potent cytotoxic T lymphocytes (32), the development of strategies to 
suppress DCs is expected to improve current immunotherapies. siRNA-based knockdown of endogenous immunostimulatory factors is a promising strategy for modulation of the immunogenic functions of DCs for use in therapeutic strategies such as immunosuppression.

The present study described an efficient method to regulate Cx43 expression via electroporation-mediated siRNA transfection into immature DCs. A specific siRNA duplex was identified with the ability to knockdown Cx43 at the mRNA and protein level. Due to the fact that RNAi is a potent method that requires only a small number of dsRNA molecules per cell to silence repression, RNAi technology is superior to anti-sense oligonucleotide, genetic engineering or antibody-blocking approaches (32). Of note, under certain circumstances, siRNAs may directly stimulate immunity by initiating DC maturation $(33,34)$; however, this is not a general effect of the siRNA but is dependent on the sequence of the duplex and is therefore considered to be an additional biological activity of siRNA. For this reason, these siRNAs are referred to as immunostimulatory siRNAs (isRNAs) (33). In the present study, a marginal increase in Cx43 mRNA expression levels in DCs transfected with non-silencing siRNA was demonstrated.

APCs acquire information in the form of antigens from infected cells in their periphery and subsequently migrate to lymph nodes to specifically stimulate cytotoxic $\mathrm{T}$ lymphocytes by antigen presentation and expression of specific co-stimulatory molecules, leading to the activation and expansion of the cytotoxic T-lymphocytes $(35,36)$. Activated monocytes have been demonstrated to acquire antigenic information in the form of peptides from influenza-infected cells through the gap junction (16). The present study showed that knockdown of Cx43 in DCs significantly reduced their capacity to stimulate T-cell proliferation, thereby contributing to the elucidation of the function of $\mathrm{Cx} 43$ in DCs during the activation of T-cell proliferation.

The present study was the first to demonstrate that RNAi can be successfully applied to block Cx43 expression in DCs. siRNA-mediated silencing of Cx43 equipped DCs with 'tolerogenic' properties. This approach may be a promising strategy for immunotherapy.

\section{Acknowledgements}

The present study was supported by grants from the National Natural Science Foundation of China (no. 30670866).

\section{References}

1. Hart DN: Dendritic cells: Unique leukocyte populations which control the primary immune response. Blood 90: 3245-3287, 1997.

2. Shortman K and Liu YJ: Mouse and human dendritic cell subtypes. Nat Rev Immunol 2: 151-161, 2002.

3. Mellman I and Steinman RM: Dendritic cells: Specialized and regulated antigen processing machines. Cell 106: 255-258, 2001.

4. Steinman RM, Hawiger D and Nussenzweig MC: Tolerogenic dendritic cells. Annu Rev Immunol 21: 685-711, 2003.

5. Bennett MV, Contreras JE, Bukauskas FF and Sáez JC: New roles for astrocytes: Gap junction hemichannels have something to communicate. Trends Neurosci 26: 610-617, 2003.

6. Saez JC, Berthoud VM, Branes MC, Martinez AD and Beyer EC: Plasma membrane channels formed by connexins: Their regulation and functions. Physiol Rev 83: 1359-1400, 2003.
7. Harris AL: Emerging issues of connexin channels: Biophysics fills the gap. Q Rev Biophys 34: 325-472, 2001.

8. Evans WH, De Vuyst E and Leybaert L: The gap junction cellular internet: Connexin hemichannels enter the signalling limelight. Biochem J 397: 1-14, 2006.

9. Krenács T and Rosendaal M: Immunohistological detection of gap junctions in human lymphoid tissue: Connexin43 in follicular dendritic and lymphoendothelial cells. J Histochem Cytochem 43: 1125-1137, 1995.

10. Krenacs $\mathrm{T}$ and Rosendaal M: Gap-junction communication pathways in germinal center reactions. Dev Immunol 6: 111-118, 1998.

11. Nihei OK, Campos de Carvalho AC, Spray DC, Savino W and Alves LA: A novel form of cellular communication among thymic epithelial cells: Intercellular calcium wave propagation. Am J Physiol Cell Physiol 285: C1304-C1313, 2003.

12. Alves LA, Nihei OK, Fonseca PC, Carvalho AC and Savino W: Gap junction modulation by extracellular signaling molecules: The thymus model. Braz J Med Biol Res 33: 457-465, 2000.

13. Wong CW, Christen T and Kwak BR: Connexins in leukocytes: Shuttling messages? Cardiovasc Res 62: 357-367, 2004.

14. Oviedo-Orta E, Errington RJ and Evans WH: Gap junction intercellular communication during lymphocyte transendothelial migration. Cell Biol Int 26: 253-263, 2002.

15. Eugenín EA, Brañes MC, Berman JW and Sáez JC: TNF-alpha plus IFN-gamma induce connexin43 expression and formation of gap junctions between human monocytes/macrophages that enhance physiological responses. J Immunol 170: 1320-1328, 2003.

16. Neijssen J, Herberts C, Drijfhout JW, Reits E, Janssen L and Neefjes J: Cross-presentation by intercellular peptide transfer through gap junctions. Nature 434: 83-88, 2005.

17. Kumar P, Ban HS, Kim SS, Wu H, Pearson T, Greiner DL, Laouar A, Yao J, Haridas V, Habiro K, et al: T cell-specific siRNA delivery suppresses HIV-1 infection in humanized mice. Cell 134: 577-586, 2008.

18. Chhabra A, Chakraborty NG and Mukherji B: Silencing of endogenous IL-10 in human dendritic cells leads to the generation of an improved CTL response against human melanoma associated antigenic epitope, MART-1 27-35. Clin Immunol 126: 251-259, 2008

19. El-Armouche A, Singh J, Naito H, Wittköpper K, Didié M, Laatsch A, Zimmermann WH and Eschenhagen T: Adenovirus-delivered short hairpin RNA targeting PKCalpha improves contractile function in reconstituted heart tissue. J Mol Cell Cardiol 43: 371-376, 2007.

20. Baba K, Goto-Koshino Y, Mizukoshi F, Setoguchi-Mukai A, Fujino Y, Ohno K and Tsujimoto H: Inhibition of the replication of feline immunodeficiency virus by lentiviral vector-mediated RNA interference in feline cell lines. J Vet Med Sci 70: 777-783, 2008.

21. Liu G, Ng H, Akasaki Y, Yuan X, Ehtesham M, Yin D, Black KL and Yu JS: Small interference RNA modulation of IL-10 in human monocyte-derived dendritic cells enhances the Th1 response. Eur J Immunol 34: 1680-1687, 2004.

22. Chen X, He J and Chang LJ: Alteration of T cell immunity by lentiviral transduction of human monocyte-derived dendritic cells. Retrovirology 1: 37, 2004.

23. Prechtel AT, Turza NM, Theodoridis AA, Kummer M and Steinkasserer A: Small interfering RNA (siRNA) delivery into monocyte-derived dendritic cells by electroporation. J Immunol Methods 311: 139-152, 2006.

24. Jantsch J, Turza N, Volke M, Eckardt KU, Hensel M, Steinkasserer A, Willam C and Prechtel AT: Small interfering RNA (siRNA) delivery into murine bone marrow-derived dendritic cells by electroporation. J Immunol Methods 337: 71-77, 2008.

25. SumimotoH,TsujiT,MiyoshiH,HagiharaM,Takada-YamazakiR, Okamoto S, Ikeda Y, Takahashi T and Kawakami Y: Rapid and efficient generation of lentivirally gene-modified dendritic cells from DC progenitors with bone marrow stromal cells. J Immunol Methods 271: 153-165, 2002.

26. Elbashir SM, Harborth J, Lendeckel W, Yalcin A, Weber K and Tuschl T: Duplexes of 21-nucleotide RNAs mediate RNA interference in cultured mammalian cells. Nature 411: 494-498, 2001.

27. Matsue H, Yao J, Matsue K, Nagasaka A, Sugiyama H, Aoki R, Kitamura M and Shimada S: Gap junction-mediated intercellular communication between dendritic cells (DCs) is required for effective activation of DCs. J Immunol 176: 181-190, 2006. 
28. Mendoza-Naranjo A, Saéz PJ, Johansson CC, Ramírez M Mandakovic D, Pereda C, López MN, Kiessling R, Sáez JC and Salazar-Onfray F: Functional gap junctions facilitate melanoma antigen transfer and cross-presentation between human dendritic cells. J Immunol 178: 6949-6957, 2007.

29. Guan X, Cravatt BF, Ehring GR, Hall JE, Boger DL, Lerner RA and Gilula NB: The sleep-inducing lipid oleamide deconvolutes gap junction communication and calcium wave transmission in glial cells. J Cell Biol 139: 1785-1792, 1997.

30. Guan X, Wilson S, Schlender KK and Ruch RJ: Gap-junction disassembly and connexin 43 dephosphorylation induced by 18 beta-glycyrrhetinic acid. Mol Carcinog 16: 157-164, 1996.

31. Montecino-Rodriguez $\mathrm{E}$, Leathers $\mathrm{H}$ and Dorshkind $\mathrm{K}$ : Expression of connexin 43 (Cx43) is critical for normal hematopoiesis. Blood 96: 917-924, 2000.

32. Ichim TE, Zhong $\mathrm{R}$ and Min WP: Prevention of allograft rejection by in vitro generated tolerogenic dendritic cells. Transpl Immunol 11: 295-306, 2003.
33. Hornung V, Guenthner-Biller M, Bourquin C, Ablasser A, Schlee M, Uematsu S, Noronha A, Manoharan M, Akira S, de Fougerolles A, et al: Sequence-specific potent induction of IFN-alpha by short interfering RNA in plasmacytoid dendritic cells through TLR7. Nat Med 11: 263-270, 2005.

34. Prechtel AT, Turza NM, Theodoridis AA and Steinkasserer A: CD83 knockdown in monocyte-derived dendritic cells by small interfering RNA leads to a diminished $\mathrm{T}$ cell stimulation. J Immunol 178: 5454-5464, 2007.

35. Randolph GJ, Sanchez-Schmitz G and Angeli V: Factors and signals that govern the migration of dendritic cells via lymphatics: Recent advances. Springer Semin Immunopathol 26: 273-287, 2005.

36. Sumen C, Mempel TR, Mazo IB and von Andrian UH: Intravital microscopy: Visualizing immunity in context. Immunity 21: 315-329, 2004. 